\title{
Plasma-catalyzed Liquefaction of Wood-based Biomass
}

\begin{abstract}
Xiaohang Sun, ${ }^{\mathrm{a}, \mathrm{b}}$ Zijun Sun, ${ }^{\mathrm{a}, \#}$ Yanbin Xin, ${ }^{\mathrm{a}}$ Bing Sun, ${ }^{\mathrm{a}, *}$ and Xiaomin Lu ${ }^{\mathrm{b}}$
Biomass resources in nature produce a large amount of waste resources (agricultural residues, wood waste, etc.) during agricultural and forestry production processes. Therefore, the effective utilization of these solid biomass waste resources has attracted widespread interest. In this paper, a pulsed discharge plasma technology was used to perform catalytic liquefaction experiments on solid biomass sawdust at room temperature and atmospheric pressure, and the reaction parameters such as the solid:liquid ratio, liquefaction solvent ratio, and catalyst ratio were optimized. The results showed that the plasma technology achieved a higher liquefaction yield; the optimized reaction parameters were: a solid:liquid ratio of 1:23.4, a liquefaction solvent polyethylene glycol (PEG) / glycerol (GL) ratio of 25:15 (V:V), and an acid volume fraction of $0.188 \%$. In addition, the characteristics of the products of the liquefaction reaction were analyzed and discussed. The liquid products were mainly composed of small molecules. The experiment established that the liquefaction of solid sawdust by high-voltage pulsed discharge plasma can be an effective technical method.
\end{abstract}

Keywords: Biomass liquefaction; Plasma catalysis; High-voltage pulsed discharge; Cellulose; Lignin

Contact information: a: College of Environmental Science and Engineering, Dalian Maritime University, Dalian 116026, China; $b$ : College of Nature Resources, Department of Forest Biomaterials, North Carolina State University, Raleigh, NC, 27695 USA;

* Corresponding author: sunb88@dlmu.edu.cn; \# the same contribution as first author

\section{INTRODUCTION}

Biomass liquefaction is a promising technology for the conversion of biomass into liquid biofuels and biochemicals. In past decades, research on solvolysis techniques for chemically converting whole wood components into soluble materials has been undertaken (Yoshioka and Shiraishi 1993; Ono and Sudo 1997; Shiraishi et al. 2000; Yamada and Ono 2001; Yamada et al. 2007; Lu 2019). The fuel oil produced by biomass liquefaction not only can be used as fuel, but it can also be converted to many chemical products, which are used to prepare raw materials for polymeric resins, molding materials, and adhesives. Due to the threats of energy shortage and global warming, the development and utilization of biomass energy have become research hotspots. Many scholars have explored efficient and practical methods of biomass liquefaction, such as direct liquefaction (Wang et al. 2007), supercritical liquefaction/subcritical liquefaction (Yuan et al. 2007; Yin et al. 2010), microwave-assisted liquefaction (Wan et al. 2009; Lu et al. 2016), and solvent catalytic liquefaction (Yamada and Ono 2001; Yamada et al. 2007).

Maldas and Shiraishi (1997) used alkali and salt as catalysts to catalyze phenol liquefaction biomass under atmospheric pressure, and the results showed that the highest liquefaction yield was obtained at a biomass to liquid ratio of 6:4. Using supercritical methanol as a solvent medium, Minami and Saka (2003) studied the differences in 
supercritical liquefaction behavior between cork and hardwood, and they also investigated the reason for the difference in liquefaction yield under identical reaction conditions. Li et al. (2015) compared the single liquefaction and mixed co-liquidation of five biomass feedstocks (cottonwood, fir, moso bamboo, straw, and hemp core) in polyols with a microwave-assisted method and investigated the effects of biomass type on the liquefaction behavior of polyols via the microwave-assisted method. The results show that the mixed biomass has a synergistic effect in the process of polyol coliquidation that promotes the liquefaction of single biomass, which is difficult to liquefy. Lu et al. (2016) successfully used microwave-ultrasonic-assisted technology (MUAT) to achieve a fast liquefaction catalytic system for wood chips in a sulfuric acid/polyethylene glycol system. The effects of some key parameters on the liquefaction yield were studied. The liquefaction time was successfully reduced from $60 \mathrm{~min}$ to $20 \mathrm{~min}$, and the liquefaction yield reached a peak of 91\%. Notably, both microwave-catalyzed liquefaction and ultrasonic-assisted liquefaction are expensive and require complex equipment.

Although the traditional biomass liquefaction process has been extensively studied, it mainly adopts the high temperature and/or high-pressure method, which has the disadvantages of high energy consumption, long reaction time, and high cost (Cheng et al. 2010; Yin et al. 2010; Brand and Kim 2015). Therefore, developing new biomass liquefaction technology is urgent. In particular, rapid liquefaction under atmospheric pressure must be achieved to replace the traditional liquefaction method with simpler and more efficient liquefaction methods. Due to the aforementioned reasons, plasma liquefaction biomass technology has attracted much attention.

In recent years, plasma technology has developed rapidly. The unique chemical activity and high reactivity of plasma have enabled many chemical reactions that are traditionally difficult or impossible to achieve (Sun et al. 1997, 2006; Zhou et al. 2016). Attempts have been made to apply plasma technology to the thermal conversion of biomass. Yi et al. (2006) used plasma to study the rapid pyrolysis and liquefaction of biomass. Tang and Huang (2005) used wood chips as raw materials and adopted radio frequency (RF) capacitively coupled plasma technology to achieve biomass gasification. Steinberg (2006) used plasma technology to convert fossil fuels and biomass into electricity, hydrogen, and liquid fuels. Recently, Xi et al. (2017) and Jiang et al. (2019) combined plasma electrolysis in the presence of sulfuric acid as the catalyst with traditional polyethylene glycol 200 (PEG 200) and glycerol co-solvent liquefaction to achieve fast liquefaction of biomass sawdust. The results show that the plasma electrolysis liquefaction process causes sawdust to decompose into small molecules in liquid and gas forms, which is directly related to the changes in solution resistance parameters in the plasma electrolysis liquefaction process. Their research indicates that only $140 \mathrm{~s}$ are needed to achieve a $100 \%$ liquefaction yield at an energy cost of 0.00642 $\mathrm{kWh}$, whereas the conventional liquefaction treatment requires $90 \mathrm{~min}$ at an energy cost of $1.6 \mathrm{kWh}$. This shows that plasma technology achieves not only a higher liquefaction yield but also a higher energy efficiency.

In view of the effectiveness of plasma liquefaction of biomass, this paper focused on the use of high-voltage pulses to directly generate plasma in liquids to study the liquefaction characteristics of waste biomass pine wood chips and the effects of plasma and solution parameters on liquefaction yields. This study aimed to verify that the high-voltage pulsed discharge (HVPD) in liquid liquefaction technology is an effective way to liquefy biomass. 


\section{EXPERIMENTAL}

\section{Materials}

In the experiment, the waste pine wood chips produced in the production process were used. The pine chips were dried in an oven at $105^{\circ} \mathrm{C}$ for $3 \mathrm{~h}$ to remove water in the chips. It was found that the mass of the pine chips basically does not change after drying for 3 hours, indicating that the moisture has been removed. Then, they were crushed, sieved, and separated and selected with a 100-mesh sieve. The sieved fine sawdust powder was used as a biomass raw material to be treated. In addition, concentrated sulfuric acid (98\%, analytical grade), ethanol (anhydrous, analytical grade), and glycerol (GL, analytical grade) were purchased from Kermel Chemical Reagent Co., Ltd., Tianjin, China and solvent polyethylene glycol 200 (PEG, analytical grades) was purchased from Tianjin Chemical Reagent Factory, Tianjin, China. All these reagents were used as received without further purification. Except for the special declared conditions, the composition of liquefaction mixtures was a liquefaction solvent polyethylene glycol (PEG) to glycerol (GL) ratio of $25: 15(\mathrm{~V}: \mathrm{V})$. The acid volume fraction was $0.188 \%$, and the mass of pine sawdust of $150 \mu \mathrm{m}$ size was $2 \mathrm{~g}$.

\section{Experimental Setup and Methods}

An overall schematic diagram of the experimental setup for this experiment is shown in Fig. 1. The high voltage pulsed discharge plasma liquefaction system was composed of high-voltage pulse power, a quartz glass reactor, a high-voltage test probe, a current probe, and an oscilloscope.

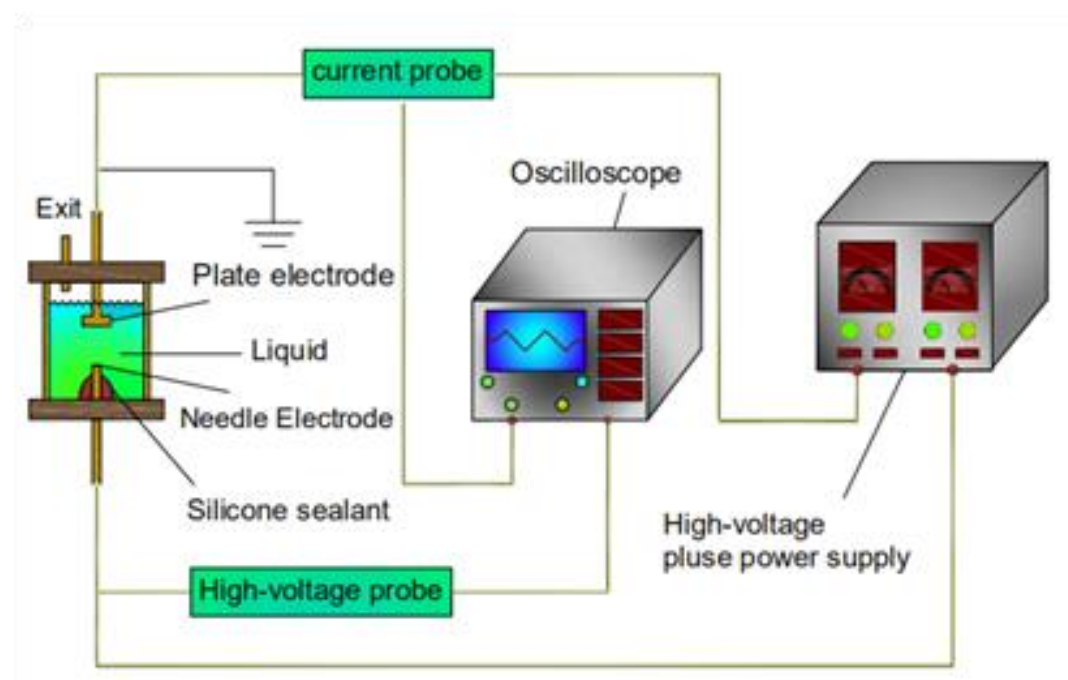

Fig. 1. Schematic diagram of the liquefaction device

The quartz glass chamber had a thickness of $10 \mathrm{~mm}$, an inner diameter of $40 \mathrm{~mm}$, and a height of $50 \mathrm{~mm}$. The top and bottom were fixed with a 10 -mm-thick Plexiglas plate. The reactor was a needle-plate structure, the plate electrode was a stainless steel plate, the needle electrode was a platinum needle, and the needle was wrapped with a silicone sealant. The stainless steel plate and needle of the reactor were connected to a pulsed high-voltage power source directly with two electrodes, and the electrode distance was $6 \mathrm{~mm}$. The peak voltage of the power supply was adjustable from 0 to $50 \mathrm{kV}$. When 
the peak voltage was $32 \mathrm{kV}$ and the frequency was $50 \mathrm{~Hz}$, a more ideal continuous stable discharge state was achieved.

Polyethylene glycol 200 and glycerol were used as liquefaction agents and mixed with biomass raw material pine sawdust in a quartz reactor, and concentrated sulfuric acid was used as a reaction catalyst for the biomass liquefaction experiment.

After the plasma discharge was complete, the temperature of the treated solution was measured using a thermometer. The discharged solution was collected, centrifuged at $4000 \mathrm{r} / \mathrm{min}$ in a centrifuge for $15 \mathrm{~min}$, and the supernatant was taken as a liquid product for subsequent characterization. The liquid precipitated in the lower layer was diluted with distilled water and filtered with a vacuum pump to isolate the solid residue. The filter residue was washed with ethanol several times until the liquid was colorless after washing. The obtained solid residue was dried in an oven at $105{ }^{\circ} \mathrm{C}$ for $12 \mathrm{~h}$, collected, and weighed, and the final solid product was calculated. The liquefaction yield (\%) was expressed as Eq. 1,

$f=\left(1-m_{1} / m_{2}\right)$

where $f$ represents the liquefaction yield (\%), $m_{1}$ is the mass (g) of the solid residue, and $m_{2}$ is the total mass $(\mathrm{g})$ of the sawdust.

A scanning electron microscope (SEM, FEI Helios DualBeam, Thermo Fisher Scientific, USA) and an optical microscope (N-300M, Ningbo Yongxin Optics Co., Ltd, Ningbo, China) were used to observe the microstructure of raw sawdust, solid residue, and liquefied product. The Fourier-transform infrared (FTIR) spectrum of the sawdust liquid product after the plasma reaction was obtained using FTIR spectroscopy (Nicolet 6700, Thermo Fisher Scientific, USA).

The content of cellulose and lignin in sawdust was determined by the paradigm acid washing method. Principle: The Van Soest (1963) cellulose content determination method determines the neutral detergent fiber (NDF) and acid detergent fiber (ADF). The botanical feed is treated with a neutral detergent, and the insoluble residue is neutral detergent fiber, which is mainly composed of cell wall components, including hemicellulose, cellulose, lignin, and silicate. The plant feed is treated with an acid detergent, and the remaining residue is acid detergent fibers, which include cellulose, lignin, and silicate.

The residue of the acid washed fiber treated with $72 \%$ sulfuric acid is lignin and silicate, and the residue of $72 \%$ sulfuric acid treated subtracted from the acid washed fiber value is the cellulose content of the feed. The residue after $72 \%$ sulfuric acid treatment is ashed, and the part escaping in the ashing process is the content of acid detergent lignin (ADL).

\section{RESULTS AND DISCUSSION}

\section{Catalytic Liquefaction of Pulsed Discharge Plasma}

Applying a pulsed high voltage between two electrodes immersed in the liquid ionizes the liquid to generate plasma, and the discharge process produces four effects, namely high-voltage electric fields, various free radicals, ultraviolet light, and shock wave effects (Sun et al. 2018). The high-voltage electric field accelerates electrons to generate high-energy electrons. High-energy electrons can collide with a large number of molecules to directly break chemical bonds, and the process generates various free 
radicals, such as $\mathrm{O}$ and $\mathrm{H}$, that can produce redox reactions with large molecules. The ultraviolet light generated can also directly break large molecular bonds. In addition, the shock wave can generate many micro-bubbles in the solution, and the supercritical "cavitation" effect is generated in the micro-bubbles during the rupture process; all these effects promote the chemical reaction to complete liquefaction to varying degrees.

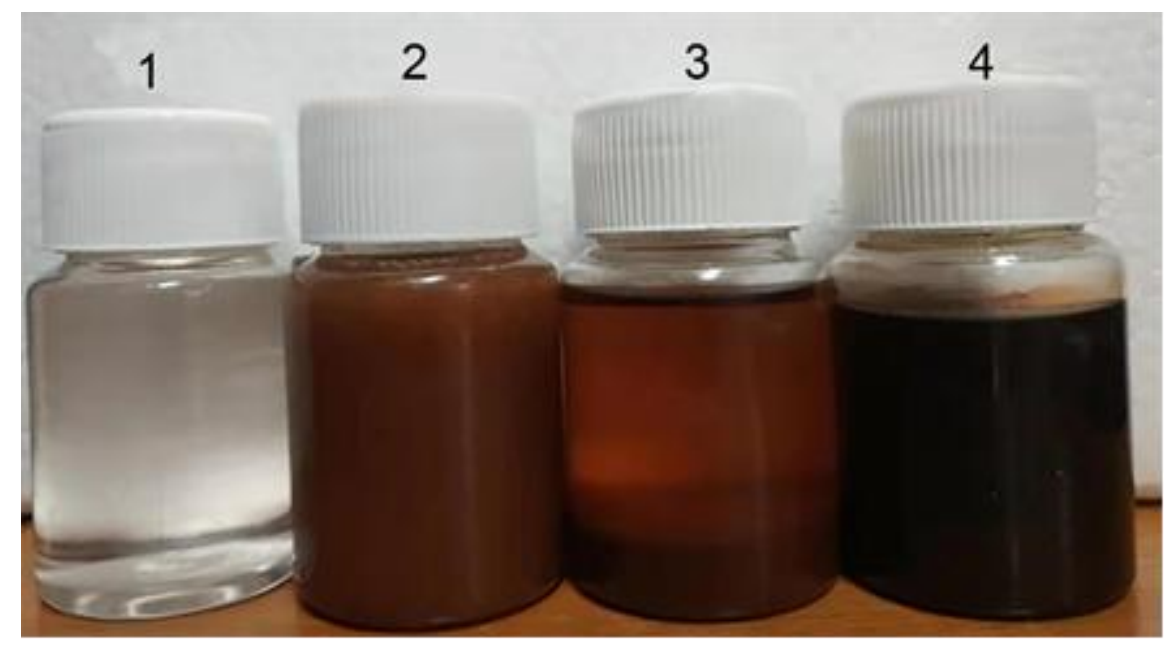

Fig. 2. Photos of sawdust before and after treatment by HVPD. Sample 1: liquefaction solution (polyethylene glycol, glycerol, and concentrated sulfuric acid mixed system) without sawdust powder; sample 2: a state of homogeneous stirring of sample 1 with $2 \mathrm{~g}$ of sawdust added; sample 3: sample 2 after $3 \mathrm{~h}$ of standing; sample 4: the sample treated with HVPD for 12 min after $3 \mathrm{~h}$ of standing

Figures 2 and 3 show the liquefaction characteristics of high-voltage pulsed liquid-phase discharge biomass sawdust. The peak voltage used was $32 \mathrm{kV}$, the frequency was $50 \mathrm{~Hz}$.

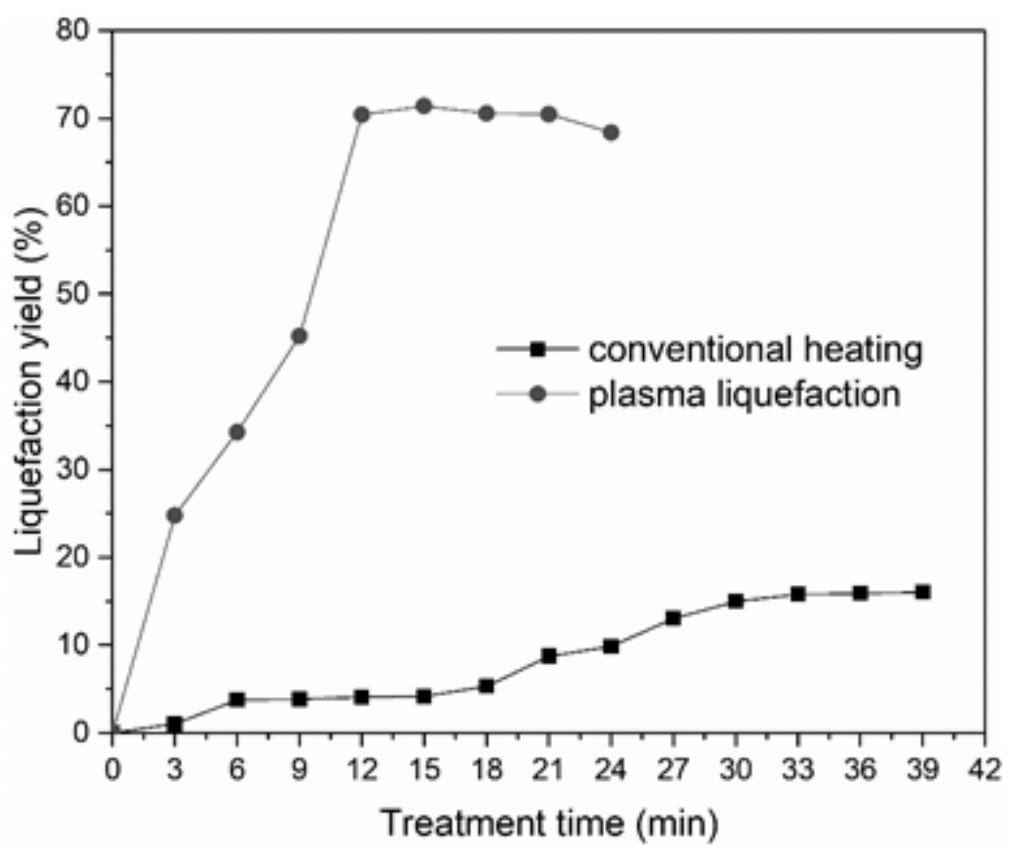

Fig. 3. Change in the liquefaction yield of plasma and conventional heating 
The composition of liquefaction mixtures is a liquefaction solvent polyethylene glycol (PEG) / glycerol (GL) ratio of 25:15 (V:V), and an acid volume fraction of $0.188 \%$ the pine sawdust of $150 \mu \mathrm{m}$ size is $2 \mathrm{~g}$. Figure 2 shows that the untreated sample had undergone precipitation after standing for $3 \mathrm{~h}$, whereas the sample treated with plasma for 12 min became dark brown, and the solution system became homogeneous. After $3 \mathrm{~h}$ of standing, no precipitation or separation layer phenomenon appeared. Therefore, the physical and chemical properties of the solid powder sawdust may have changed.

Figure 3 shows that when using pulsed discharge plasma for biomass liquefaction, the liquefaction yield after 3 min reached $28.4 \%$, which far exceeded the maximum liquefaction yield of traditional oil bath heating (liquefaction temperature $82{ }^{\circ} \mathrm{C}$ ). The liquefaction yield reached $45.2 \%$ when the liquefaction time was $9 \mathrm{~min}$, and the rapid growth rate in the next 3 min increased to $55.7 \%$. During this time, the plasma discharge likely generated a large number of free radicals and ultraviolet light, which caused large molecules to break into small molecular chemicals. As treatment time increased, the liquefaction yield also increased, and it reached a peak of $71.4 \%$ in 12 min. Then, the liquefaction yield showed a slow downward trend.

Many experimental studies have shown that temperature is an important factor in the liquefaction of biomass. A thermometer was used to measure the temperature of the solution after the plasma reaction. The temperature of the liquid before discharge was room temperature, the temperature of treatment solution gradually increased during the discharge, and the maximum temperature at the end of the discharge was $82{ }^{\circ} \mathrm{C}$. In order to rule out the pure thermal liquefaction at lower temperatures and understand the pure catalytic effect of plasma, the traditional oil bath heating method was used to investigate the heating liquefaction effect.

The temperature of the plasma treatment solution increased with the as discharge time increased, and the maximum temperature was $82{ }^{\circ} \mathrm{C}$. To distinguish between the catalytic liquefaction effect of plasma and the traditional heating liquefaction effect, the conventional solution was heated under normal pressure to the same temperature as the maximum temperature of the plasma treatment, and the liquefaction yield was measured. Figure 3 shows the trend of the liquefaction yield of liquefied biomass under conventional heating at $82{ }^{\circ} \mathrm{C}$ as a function of treatment time. The heating rate of traditional heating was $15^{\circ} \mathrm{C} / \mathrm{min}$. The pulsed discharge plasma liquefied biomass was compared with it.

Figure 3 shows that the liquefaction yield during traditional heating suddenly increased from $5.32 \%$ to $8.76 \%$ at $18 \mathrm{~min}$ to $21 \mathrm{~min}$, which was the highest growth rate in the entire measurement range for a $3 \mathrm{~min}$ period, but it rose slowly prior to $18 \mathrm{~min}$. After $33 \mathrm{~min}$, the liquefaction yield reached $15.8 \%$, and after that, there was almost no change. Therefore, the liquefaction yield achieved by liquefying biomass at $82{ }^{\circ} \mathrm{C}$ using a simple heating method was small.

The comparison of the two curves in Fig. 3 shows that the conventional heating effect under $82{ }^{\circ} \mathrm{C}$ did not efficiently liquefy biomass to achieve a high liquefaction yield. The high liquefaction yield in this experiment was mainly due to plasma-catalyzed liquefaction rather than the thermal effect of plasma. The thermal effect was not more than $10 \%$. Therefore, the liquefaction of biomass by pulsed discharge plasma was found to be a relatively efficient, simple, and fast processing method. 


\section{Effect of Wood Particle Size on Liquefaction Yield}

To study the effect of the particle size of the waste biomass raw material sawdust on the liquefaction yield, the raw materials of different particle sizes were screened using a sieve to conduct experiments.

Table 1. Relationship between Nominal Particle Size and Particle Size Range

\begin{tabular}{cc}
\hline $\begin{array}{c}\text { Nominal raw material } \\
\text { particle size }(\mu \mathrm{m})\end{array}$ & Actual particle size range $(\mu \mathrm{m})$ \\
\hline 124 & $\geq 124$ \\
150 & $124--150$ \\
178 & $149--178$ \\
250 & $177--250$ \\
420 & $249--420$ \\
\hline
\end{tabular}

As shown in Table 1, the particle size of $150 \mu \mathrm{m}$ used in the experiment here does not refer to the average particle size, but uniformly refers to the particle size passing through the $150 \mu \mathrm{m}$ sieve without passing through $124 \mu \mathrm{m}$ as the particle size of $150 \mu \mathrm{m}$, other particle sizes, and so on. The composition of liquefaction mixtures is a liquefaction solvent polyethylene glycol (PEG) / glycerol (GL) ratio of 25:15 (V:V), and an acid volume fraction of $0.188 \%$. The results are shown in Fig. 4, which indicates that liquefaction yield increased as particle size decreased. When the particle diameter was $124 \mu \mathrm{m}$, the liquefaction yield reached $74.5 \%$. As the particle size increased, the contact area with the liquid decreased, and the liquefaction yield gradually decreased. When the particle diameter increased to $420 \mu \mathrm{m}$, the liquefaction yield decreased to $30.4 \%$. When the particle size was less than $124 \mu \mathrm{m}$, particle agglomeration occurred, and some sawdust powder underwent a simple physical dissolution phenomenon, which caused experimental data errors. To ignore the influence of the solid mass of the dissolved particles, this experiment used $150 \mu \mathrm{m}$ (100-mesh) particle diameter sawdust as the raw material for the next series of experiments.

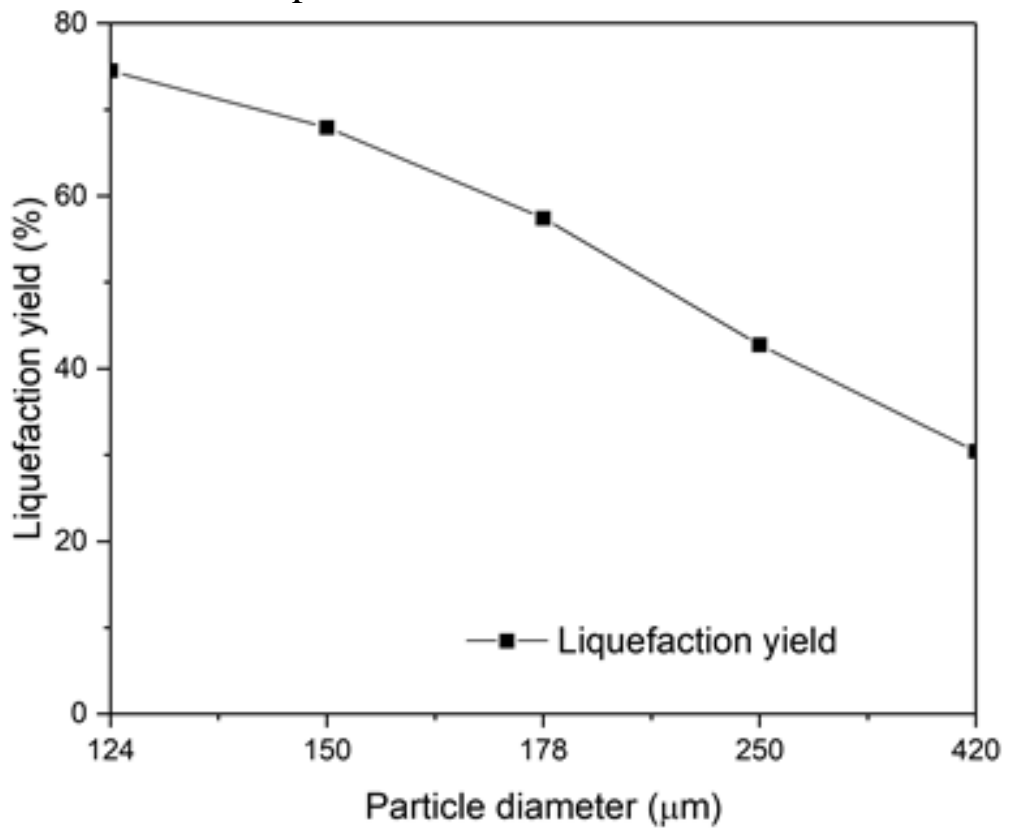

Fig. 4. Effect of sawdust particle size on liquefaction yield 


\section{Effect of Solid:Liquid Ratio on Liquefaction yield}

To treat as much biomass waste as possible in the same volume of liquefier and obtain a relatively high liquefaction yield, a solid:liquid ratio optimization experiment was performed. The experiments were performed under different solid:liquid ratios to find the optimal ratio of wood chips to liquefier. The composition of liquefaction liquid is a liquefaction solvent polyethylene glycol (PEG) / glycerol (GL) ratio of 25:15 (V:V), and an acid volume fraction of $0.188 \%$. The change curve of the solid:liquid ratio and liquefaction yield is shown in Fig. 5. The solid:liquid ratio ranged from 1:5.89 to 1:29.3. When the solid:liquid ratio was 1:5.89, the liquefaction yield was $32.8 \%$. As the content of the liquefaction agent increased, the concentration of wood chips in the liquefaction system decreased, the space for plasma-catalyzed liquefaction increased, and the liquefaction yield increased remarkably. When the solid:liquid ratio was 1:23.45, the liquefaction yield reached $70.5 \%$, and when the solid:liquid ratio was $1: 25$, the increase in the rate of the liquefaction yield became lower, and the liquefaction yield was $74.0 \%$. Therefore, reducing the concentration of solids did not contribute to the increase in liquefaction yield. In order to achieve an economic liquefaction process while maintaining the liquefaction yield in a reasonable range, a solid:liquid ratio of 1:23.45 was selected as the best solid:liquid ratio. Subsequent experiments in this paper used a solid:liquid ratio of 1:23.45.

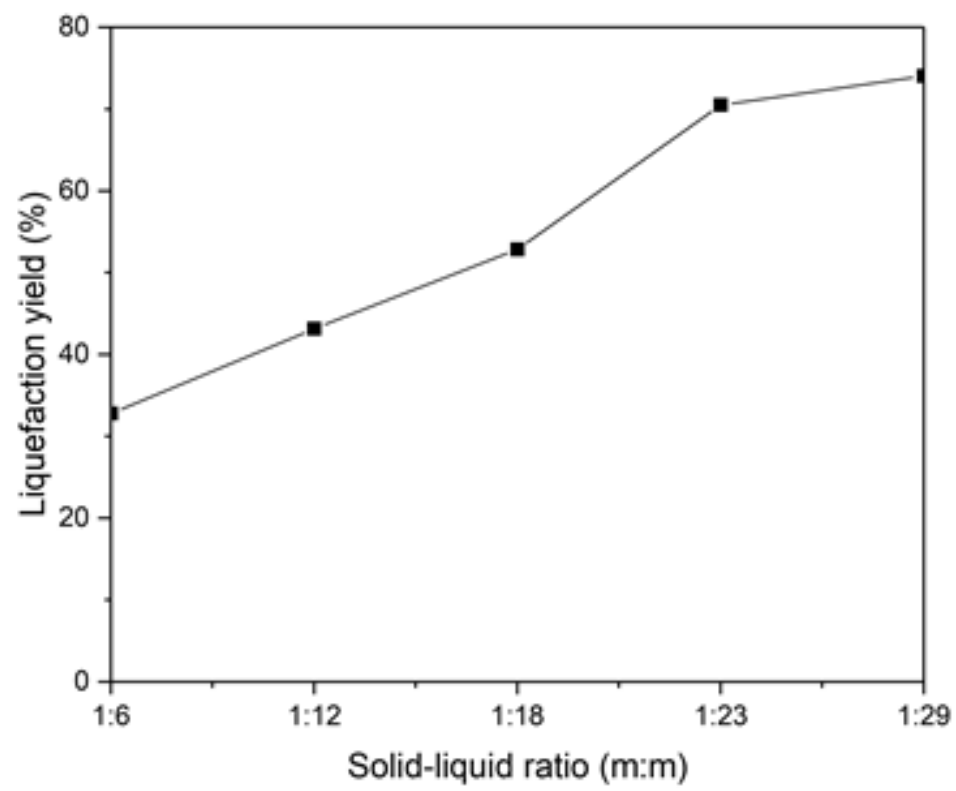

Fig. 5 Variation curve of liquefaction yield with solid:liquid ratio

\section{Effect of Polyethylene Glycol and glycerol on Liquefaction yield}

To study the effect of the relative amounts of polyethylene glycol (PEG) and glycerol (GL) on the liquefaction yield during discharge, the volume ratio of PEG:GL was varied from 0:40 to 40:0 (mL:mL). The total volume was $40 \mathrm{~mL}$, and it was not changed throughout the experiment. The volume fraction of acid was kept at $0.188 \%$. Using 100-mesh sawdust raw material with a solid:liquid ratio of 1:23.45 (m:m), $2 \mathrm{~g}$ of waste biomass sawdust was added. The results are shown in Fig. 6. Under the electric field strength of the experiment, it was difficult in pure glycerol to achieve breakdown and formation of a continuous discharge between the needle electrode and the plate 
electrode due to the strong insulation of glycerol, so the liquefaction yield was zero. When the glycerol content in the liquefaction system gradually decreased and the polyethylene glycol content continued to increase, a uniform and continuous spark discharge was generated at a fixed $32 \mathrm{kV}$ voltage, and the liquefaction yield gradually increased as the amount polyethylene glycol continued to increase. When the ratio of PEG:GL reached 25:15, the maximum liquefaction yield reached $65.3 \%$. When the polyethylene glycol content was further increased, the liquefaction yield decreased almost linearly, and the downward trend was stable. When only polyethylene glycol was present in the system and no glycerol was present, the liquefaction yield decreased to $35.4 \%$. This indicated that a small amount of glycerol could assist liquefaction. The polarity of glycerol can enhance the polarity of the entire liquefaction system, which is conducive to free radical reaction and chemical reaction, and can coordinate the liquefaction, so when the content of polyethylene glycol and glycerol cannot be too low, the liquefaction effect is better. Therefore, the ratio of 25:15 PEG:GL was judged to be the best value in the experiments.

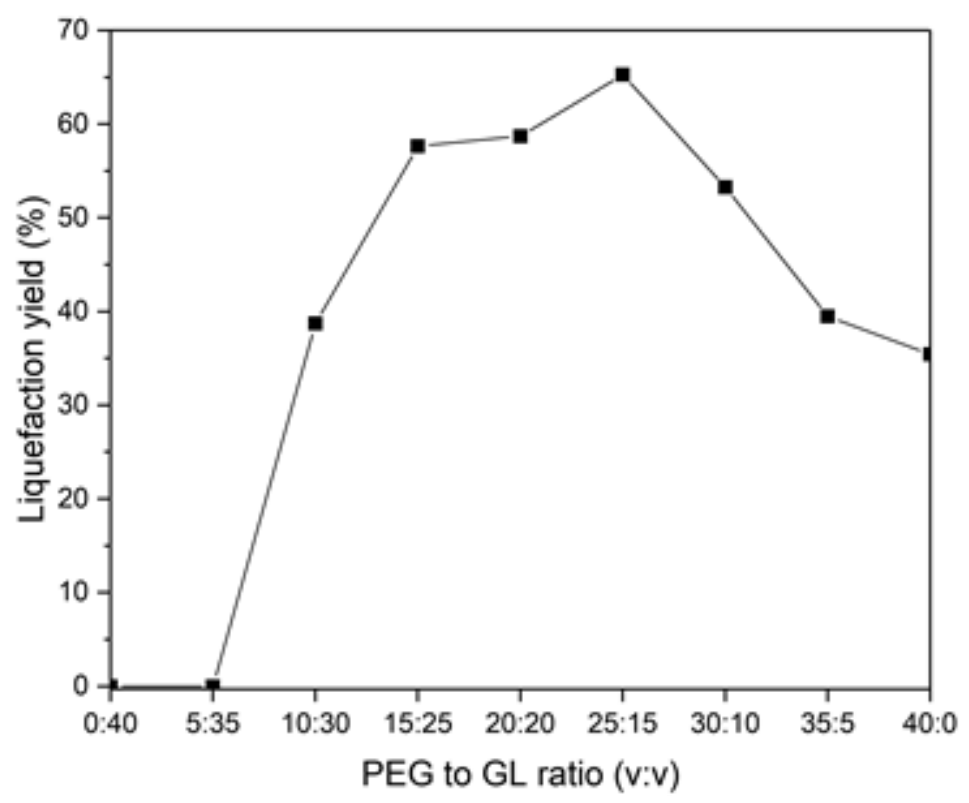

Fig. 6. Effect of $P E G / G L$ ratio on liquefaction yield

\section{Effect of the Amount of Sulfuric Acid Catalyst on the Liquefaction yield}

Adding sulfuric acid as a chemical catalyst improved the liquefaction effect, which indicated that the chemical catalyst played an important role in the liquefaction reaction. To determine the optimal catalyst content of the liquefaction system, the variation of the liquefaction yield under different sulfuric acid volume fractions was examined. The results of experiments performed with the acid volume ranging from $0 \%$ to $2.0 \%$ are shown in Fig. 6 . The liquefaction yield of the liquefaction system without the catalyst was only $28.4 \%$. As the acid content increased, the liquefaction yield gradually increased. When the acid volume fraction was $0.188 \%$, the peak liquefaction yield of the liquefaction system was $66.8 \%$. After further increasing the acid content, the biomass liquefaction yield slowly decreased, but the overall decline was relatively slow. Therefore, $0.188 \%$ sulfuric acid was the optimal catalyst content in the system to achieve the highest liquefaction yield. The other experiments in this paper all used $0.188 \%$ acid content. 


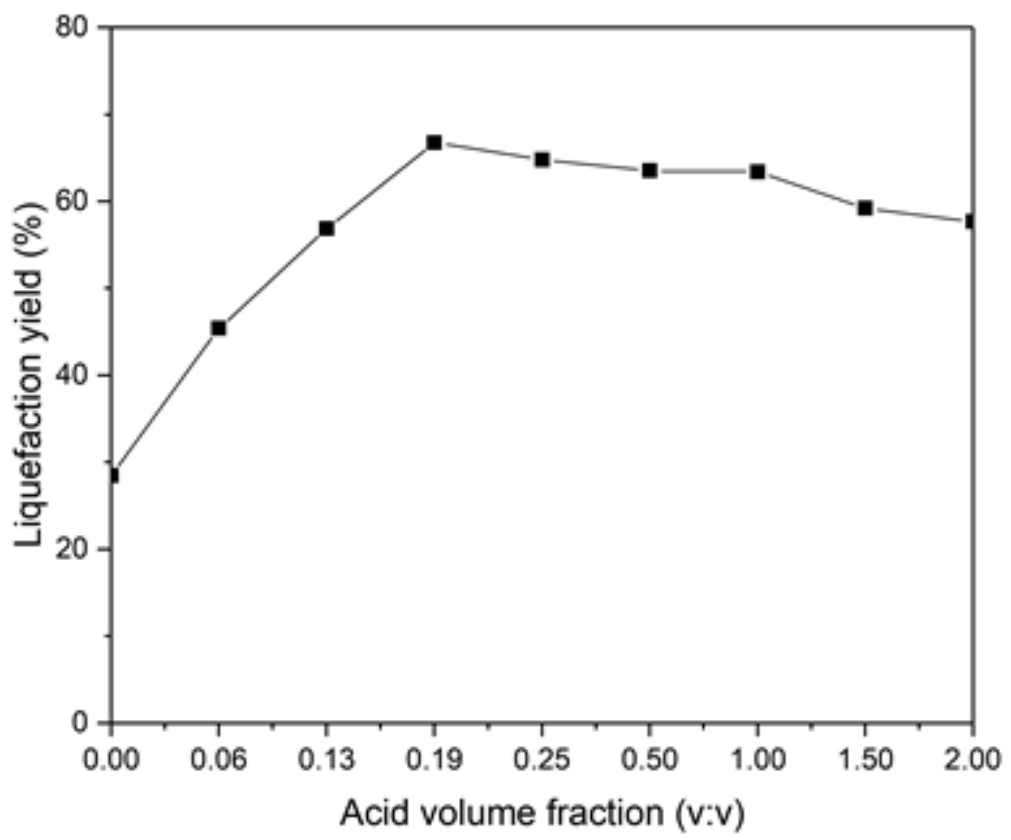

Fig. 7. Effect of catalyst content on liquefaction yield

\section{Analysis of Cellulose and Lignin}

Wood chips are composed of moisture, ash, cellulose, lignin, and hemi-cellulose, which are mainly composed of polysaccharides. Among these substances, cellulose is a linear chain (glycosidic bond)-linked polysaccharide (molecular weight higher than $5 \times$ $10^{4}$ ) composed of thousands of $\beta(1 \rightarrow 4)$ linked D-glucose groups (Klemm et al. 2005; Jiang et al. 2019). Lignin and cellulose have been extensively studied. To investigate the changes in their absolute amounts in the solution before and after plasma catalytic liquefaction, the cellulose and lignin content in raw sawdust before and after the plasma catalytic reaction were measured with Van Soest's detergent fiber analysis method. The measurement results are summarized in Table 2. The liquefaction yield of lignin in raw sawdust was $74.2 \%$. The liquefaction yield of cellulose in raw sawdust also reached $75.1 \%$ under plasma-catalyzed liquefaction. These results indicated that plasma catalytic liquefaction was an effective method.

Table 2. Changes in Cellulose and Lignin in the raw sawdust Before and After Plasma Catalytic Liquefaction

\begin{tabular}{|c|c|c|c|}
\hline Materials & $\begin{array}{c}\text { Sawdust Weight Before } \\
\text { Reaction }(\mathrm{g})\end{array}$ & $\begin{array}{c}\text { Weight After } \\
\text { Reaction }(\mathrm{g})\end{array}$ & $\begin{array}{c}\text { Liquefaction } \\
\text { yield }(\%)\end{array}$ \\
\hline Sawdust Weight & 2.0000 & 0.5800 & 71.0 \\
\hline Cellulose & 0.6904 & 0.1721 & 75.1 \\
\hline Lignin & 0.4464 & 0.1150 & 74.2 \\
\hline
\end{tabular}

\section{Analysis and Discussion of Product Characteristics}

The liquid product after plasma liquefaction is a complex composite system, which was analyzed by Jiang et al. (2019). There are more than 200 substances in the 
product, which are similar to those produced by traditional liquefaction methods (Saha et al. 2005). Liquid products can be roughly divided into five categories: (i) organic acids such as acetic acid, levulinic acid, gluconic acid, etc.; (ii) alcohols and ketones such as 2propanol, butanol, 2-hydroxy-4-methylacetophenone, etc.; (iii) sugars such as Dglucopyranose, cellobiose, etc.; (iv) ester such as butyl levulinate, glucosyl acetate, trimethyl-135-benzenetricarboxylate, etc.; (v) phenols and polyphenols such as mdiphenol.
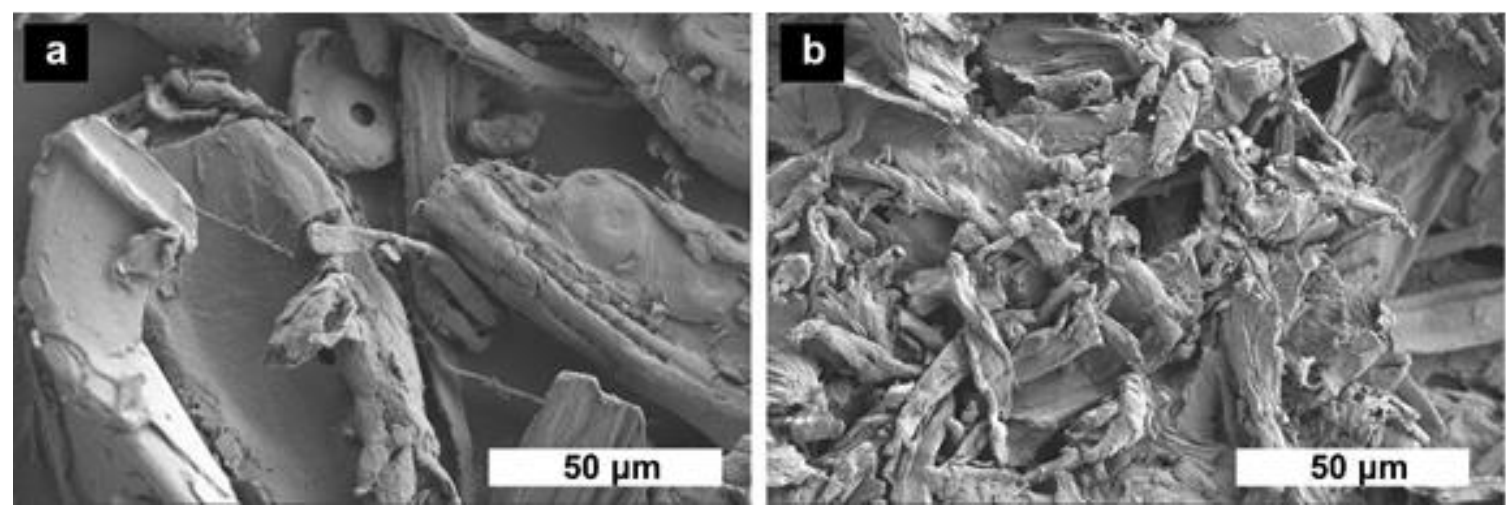

Fig. 8. The SEM images of (a) sawdust prior to liquefaction and (b) solid residues after liquefaction
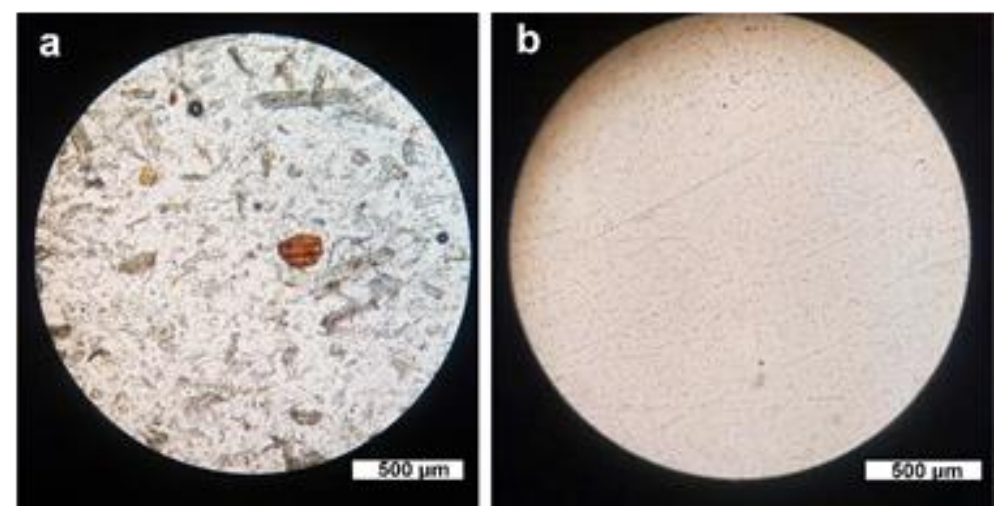

Fig. 9. Optical microscopic photos of liquids: (a) $10 \times 10$ times magnification of sawdust + PEG + GL without treatment; (b) $10 \times 10$ times magnification of liquid state after plasma discharge (after suction filtration)

SEM analysis and optical microscopy were used to observe and analyze the raw sawdust, solid residue, and liquefied product (Fig. 8 and Fig. 9, respectively). Sawdust composed of cellulose had a dense structure before liquefaction, and the size of individual particles was large (Fig. 8a). After liquefaction, the particles in the residue became finer (Fig. 8b), the block structure was looser, and the size was reduced. The liquefied liquid product is shown in Fig. 9. After the sawdust was added to the PEG and GL system, it was dispersed and slightly more diffused under the microscope than in the original sawdust state. However, in the liquid after plasma discharge treatment and suction filtration, no visible particles were observed with $10 \times 10$ optical microscopy (Fig. 9b). The block structure in the liquefied product completely disappeared.

FTIR spectra were also used to analyze the chemical properties of the sawdust liquid product (Fig. 10). Figure 10 shows that there were multiple absorption bands in the 
spectral measurement range, which indicated that the liquid product after the catalytic liquefaction reaction had rich functional groups. The strong band of $3356 \mathrm{~cm}^{-1}$ indicated strong - $\mathrm{OH} / \mathrm{-NH}$ stretching vibrations, which suggests that the liquid product was rich in aromatic hydroxyl species. This peak band was redshifted $21.85 \mathrm{~cm}^{-1}$ compared to its position before the treatment. The absorption bands at $1035 \mathrm{~cm}^{-1}$ and $1249 \mathrm{~cm}^{-1}$ should be derived from ether or phenol groups. The peaks at $1350 \mathrm{~cm}^{-1}$ and $1453 \mathrm{~cm}^{-1}$ may have been the deformation of $\mathrm{C}-\mathrm{H}$ and the vibration of aromatic rings. A clear new absorption band appeared at $1628 \mathrm{~cm}^{-1}$ at the treated liquid, which belongs to $\mathrm{C}=\mathrm{O}$ or $\mathrm{C}=\mathrm{C}$ stretching vibration band. This indicates that aromatic compounds, or products such as aldehydes and ketones had increased. These bands did not show typical cellulose and lignin in the FTIR spectrum of the liquid product. This implied that cellulose and lignin were released into the liquid as other smaller molecules by pulsed plasma discharge reaction.

In addition, the calorific value of the liquid before the reaction was $21.2 \mathrm{~kJ} / \mathrm{g}$, and the calorific value of the liquid product after the reaction was $23.5 \mathrm{~kJ} / \mathrm{g}$. The liquid produced by such a reaction system had a higher heat value of combustion than that before treatment. This showed that the system not only could turn waste solid raw materials into useful liquid bio-oils, but also it could increase the heating value of the product itself. As such, this method has very good research and development value.

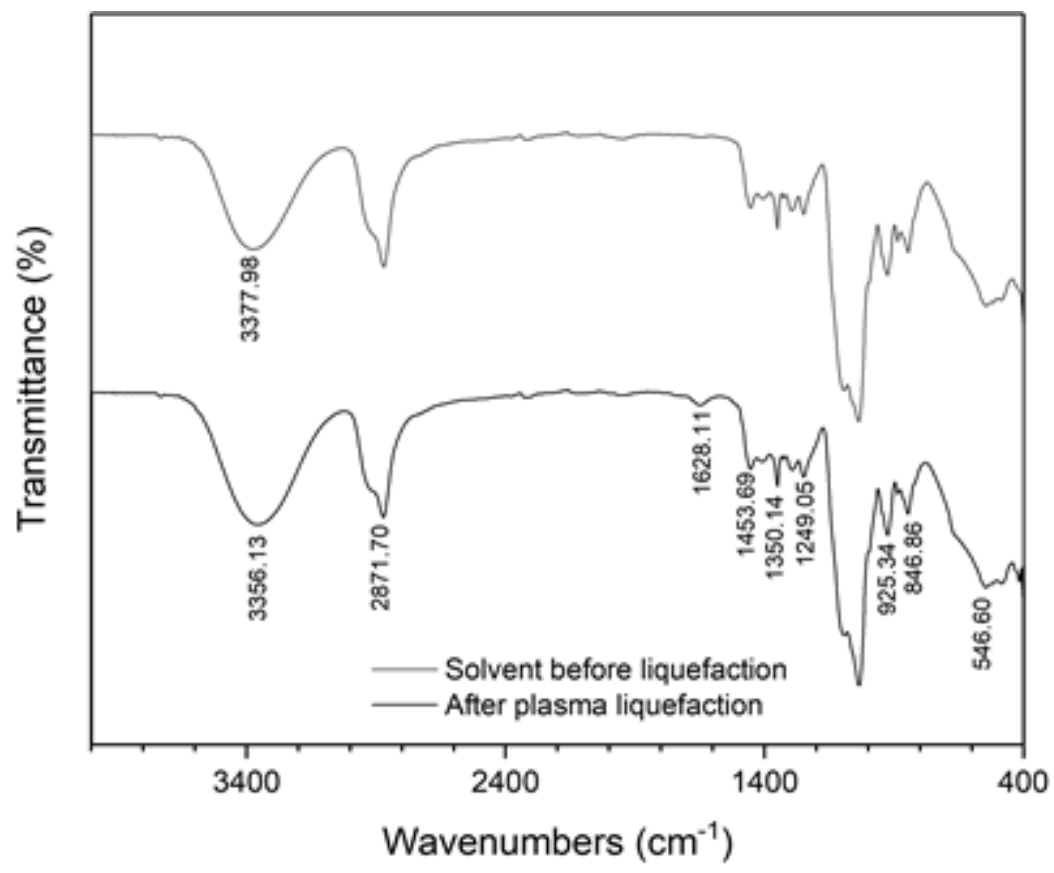

Fig. 10. The FTIR spectrum of the liquid product (Upper curve: solvent before liquefaction; Lower curve: after plasma liquefaction)

\section{CONCLUSIONS}

1. High-voltage pulsed discharge plasma catalyzed liquefaction of solid wood chips was found to be an effective technical method, and the liquefaction yield reached more than $74 \%$. 
2. Wood particle size, liquefaction agent, and catalyst concentration affected the liquefaction yield of the high-voltage pulsed discharge plasma catalytic liquefaction system. The optimized parameters were: a solid:liquid ratio of 1:23, a PEG:GL ratio of 25:15 (V:V), and an acid volume fraction of $0.188 \%$.

3. The heat generated by the discharge plasma did not play a major role in the catalytic liquefaction of the plasma, and the thermal effect was not greater than $10 \%$.

4. This experiment showed that the plasma technology could achieve a higher liquefaction yield using a simple operation. In addition, the liquefied product had a rich utilization value, which could have a profound impact on energy utilization.

\section{ACKNOWLEDGMENTS}

This work was supported by the National Natural Science Foundation (NSFC-11975063, 11675031), the National Key R\&D Program of China (2016YFC1402301), and the Fundamental Research Funds for the Central Universities (3132019329).

\section{REFERENCES CITED}

Brand, S., and Kim, J. (2015). "Liquefaction of major lignocellulosic biomass constituents in supercritical ethanol," Energy 80, 64-74. DOI:

10.1016/j.energy.2014.11.043

Cheng, S., D’Cruz, I., Wang, M., Leitch, M., and Xu, C. (2010). "Highly efficient liquefaction of woody biomass in hot-compressed alcohol-water co-solvents," Energy \& Fuels 24(9), 4659-4667. DOI: 10.1021/ef901218w

Jiang, C.-C., Liu, S.-Y., Feng, Z., Fang, Z., Zhang, X.-H., Mei, D.-H., Xi, D.-K., Luan, B.-Y., Wang, X.-Q., and Yang, S.-Z. (2019). "Plasma electrolytic liquefaction of sawdust," Chinese Physics B 28(4), Article ID 048803. DOI: 10.1088/16741056/28/4/048803

Klemm, D., Heublein, B., Fink, H.-P., and Bohn, A. (2005). "Cellulose: Fascinating biopolymer and sustainable raw material," Angewandte Chemie International Edition 44(22), 3358-3393. DOI: 10.1002/anie.200460587

Li, G. Y., Zhu, X. C., Zou, X. W., and Qin, T. F. (2015). "Microwave-assisted liquefaction of five types of biomass in polyhydric alcohols," Chemistry and Industry of Forest Products 35(1), 107-112. DOI: 10.3969/j.issn.0253-2417.2015.01.017

Lu, X. (2019). "Cellulose nanocrystals for wrinkled fabric," BioResources 14(4), 76327635. DOI: 10.15376/biores.14.4.7632-7635

Lu, Z., Wu, Z., Fan, L., Zhang, H., Liao, Y., Zheng, D., and Wang, S. (2016). "Rapid and solvent-saving liquefaction of woody biomass using microwave-ultrasonic assisted technology," Bioresource Technology 199, 423-426. DOI: 10.1016/j.biortech.2015.09.048

Maldas, D., and Shiraishi, N. (1997). "Liquefaction of biomass in the presence of phenol and $\mathrm{H}_{2} \mathrm{O}$ using alkalies and salts as the catalyst," Biomass and Bioenergy 12(4), 273279. DOI: $10.1016 /$ S0961-9534(96)00074-8 
Minami, E., and Saka, S. (2003). "Comparison of the decomposition behaviors of hardwood and softwood in supercritical methanol," Journal of Wood Science 49(1), 73-78. DOI: $10.1007 / \mathrm{s} 100860300012$

Ono, H., and Sudo, K. (1997). "The manufacturing method of the resin raw material," Japanese patent, JP2611166

Saha, B. C., Iten, L. B., Cotta, M. A., and Wu, Y. V. (2005). "Dilute acid pretreatment, enzymatic saccharification and fermentation of wheat straw to ethanol," Process Biochemistry 40(12), 3693-3700. DOI: 10.1016/j.procbio.2005.04.006

Shiraishi, N., Shirakawa, K., and Kurimoto, Y. (2000). "Methods of wood liquefaction," Japanese patent, JP3012296

Steinberg, M. (2006). "Conversion of fossil and biomass fuels to electric power and transportation fuels by high efficiency integrated plasma fuel cell (IPFC) energy cycle," International Journal of Hydrogen Energy 31(3), 405-411. DOI: 10.1016/j.ijhydene.2005.08.007

Sun, B., Kunitomo, S., and Igarashi, C. (2006). "Characteristics of ultraviolet light and radicals formed by pulsed discharge in water," Journal of Physics D: Applied Physics 39(17), 3814-3820. DOI: 10.1088/0022-3727/39/17/016

Sun, B., Sato, M., and Clements, J. S. (1997). "Optical study of active species produced by a pulsed streamer corona discharge in water," Journal of Electrostatics 39(3), 189202. DOI: 10.1016/S0304-3886(97)00002-8

Sun, B., Xin, Y., Zhu, X., Gao, Z., Yan, Z., and Ohshima, T. (2018). "Effects of shock waves, ultraviolet light, and electric fields from pulsed discharges in water on inactivation of Escherichia coli," Bioelectrochemistry 120, 112-119. DOI: 10.1016/j.bioelechem.2017.11.011

Tang, L., and Huang, H. (2005). "Biomass gasification using capacitively coupled RF plasma technology," Fuel 84(16), 2055-2063. DOI: 10.1016/j.fuel.2005.04.015

Van Soest, P. J. (1963). "Use of detergents in the analysis of fibrous feeds," Association of Official Agricultural Chemists, 46, 825.

Wan, Y., Liu, Y., Lin, X., Yang, C., Zhang, B., Chen, P., Lei, H., and Ruan, R. (2009). "Microwave assisted pyrolysis of corn stover pellets with catalysts for bio-oil production and its component," Transactions of the Chinese Society of Agricultural Engineering 25(4), 190-195. DOI: 10.3969/j.issn.1002-6819.2009.4.036

Wang, G., Li, W., Li, B., and Chen, H. (2007). "Direct liquefaction of sawdust under syngas," Fuel 86(10-11), 1587-1593. DOI: 10.1016/j.fuel.2006.11.010

Xi, D., Zhou, R., Zhou, R., Zhang, X., Ye, L., Li, J., Jiang, C., Chen, Q., Sun, G., and Liu, Q., et al. (2017). "Mechanism and optimization for plasma electrolytic liquefaction of sawdust," Bioresource Technology 241, 545-551. DOI: 10.1016/j.biortech.2017.05.132

Yamada, T., Aratani, M., Kubo, S., and Ono, H. (2007). "Chemical analysis of the product in acid-catalyzed solvolysis of cellulose using polyethylene glycol and ethylene carbonate," Journal of Wood Science 53(6), 487-493. DOI: 10.1007/s10086007-0886-8

Yamada, T., and Ono, H. (2001). "Characterization of the products resulting from ethylene glycol liquefaction of cellulose," Journal of Wood Science 47(6), 458-464. DOI: $10.1007 / \mathrm{BF} 00767898$

Yi, W., Bai, X., and Xiu, S. (2006). "The devolatilization characteristics of biomass at high heating rates," Thermophysics, Journal of Engineering 27(2), 135-138. DOI: 
Yin, S., Dolan, R., Harris, M., and Tan, Z. (2010). "Subcritical hydrothermal liquefaction of cattle manure to bio-oil: Effects of conversion parameters on bio-oil yield and characterization of bio-oil," Bioresource Technology 101(10), 3657-3664. DOI: 10.1016/j.biortech.2009.12.058

Yoshioka, M., and Shiraishi, N. (1993). "Combined liquefaction of wood and starch in a polyethylene glycol/glycerin blended solvent," Journal of the Japan Wood Research Society 39, 930-938.

Yuan, X. Z., Li, H., Zeng, G. M., Tong, J. Y., and Xie, W. (2007). "Sub- and supercritical liquefaction of rice straw in the presence of ethanol-water and 2-propanol-water mixture," Energy 32(11), 2081-2088. DOI: 10.1016/j.energy.2007.04.011

Zhou, R., Zhou, R., Wang, S., Lan, Z., Zhang, X., Yin, Y., Tu, S., Yang, S., and Ye, L. (2016). "Fast liquefaction of bamboo shoot shell with liquid-phase microplasma assisted technology," Bioresource Technology 218, 1275-1278. DOI:

10.1016/j.biortech.2016.07.042

Article submitted: March 5, 2020; Peer review completed: May 15, 2020; Revised version received and accepted: June 8, 2020; Published: June 22, 2020.

DOI: 10.15376/biores.15.3.6095-6109 